\title{
Low self-reported sports activity before stroke predicts poor one-year-functional outcome after first-ever ischemic stroke in a population-based stroke register
}

\author{
Christian Urbanek $^{1 *}$, Viola Gokel${ }^{2}$, Anton Safer ${ }^{3}$, Heiko Becher ${ }^{4}$, Armin J. Grau', Florian Buggle ${ }^{1}$ and Frederick Palm
}

\begin{abstract}
Background: Physical activity (PA) is associated with lower risk of stroke. We tested the hypothesis that lack of prestroke PA is an independent predictor of poor outcome after first-ever ischemic stroke.

Methods: We assessed recent self-reported PA and other potential predictors for loss of functional independence modified Rankin Scale (mRS) > 2 - one year after first-ever ischemic stroke in 1370 patients registered between 2006 and 2010 in the Ludwigshafen Stroke Study, a population-based stroke registry.

Results: After 1 year, 717 (52.3\%) of patients lost their independence including 251 patients (18.3\%) who had died. In multivariate logistic regression analysis lack of regular PA prior to stroke (Odds Ratio (OR) 1.7, Confidence Interval (CI) 1.1-2.5), independently predicted poor outcome together with higher age (65-74: OR 1.7; Cl 1.1-2.8, 75-

84 years: OR 3.3; Cl 2.1-5.3; $\geq 85$ years OR 14.5; Cl 7.4-28.5), female sex (OR 1.5; Cl 1.1-2.1), diabetes mellitus (OR 1.8; $\mathrm{Cl} 1.3-2.5)$, stroke severity (OR 1.2; $\mathrm{Cl} 1.1-1.2)$, probable atherothrombotic stroke etiology (OR 1.8; $\mathrm{Cl} 1.1-2.8)$ and high leukocyte count (>9.000/ $\mathrm{mm}^{3}$; OR 1.4; Cl 1.0-1.9) at admission. Subclassifying unknown stroke etiology, embolic stroke of unknown source (ESUS; $n=40$, OR 2.2; Cl 0.9-5.5) tended to be associated with loss of independence.

Conclusion: In addition to previously reported factors, lack of PA prior to stroke as potential indicator of worse physical condition, high leukocyte count at admission as indicator of the inflammatory response and probable atherothrombotic stroke etiology might be independent predictors for non-functional independence in first-ever ischemic stroke.
\end{abstract}

Keywords: Stroke, Cerebral infarction, Outcome, Physical activity, Predictors, Risk factors

\section{Background}

A high proportion of stroke survivors worldwide require assistance or are fully dependent on caregivers for activities of daily living after stroke [1]. Improved individualized therapy in acute ischemic stroke care, preemptive therapy of risk factors or changes in lifestyle prior to stroke may modify ischemic stroke (IS) outcome. Prediction of functional outcome in patients with IS can support clinicians to improve effective stroke care,

\footnotetext{
* Correspondence: christian_urbanek@hotmail.de

${ }^{1}$ Department of Neurology, University of Heidelberg, Städtisches Klinikum Ludwigshafen am Rhein, Bremserstr. 79, 67063 Ludwigshafen, Germany Full list of author information is available at the end of the article
}

anticipate discharge planning and support patients and family to develop realistic expectations for long-term care provision.

Clinical rating or imaging - based scoring systems like ASTRAL, DRAGON or SEDAN have been published to predict loss of functional independence after IS [2-5]. Age, initial stroke severity, onset to admission time, range of visual fields, level of consciousness, glucose and concentrations of serum neutrophil markers were some predictors for losing functional independence in these studies [6-11]. However, prognostic models had only minor impact on clinical practice. The majority of these scores were based on retrospective analysis of cases from

(c) The Author(s). 2018 Open Access This article is distributed under the terms of the Creative Commons Attribution 4.0 International License (http://creativecommons.org/licenses/by/4.0/) which permits unrestricted use, distribution, and reproduction in any medium, provided you give appropriate credit to the original author(s) and the source, provide a link to the Creative Commons license, and indicate if changes were made. The Creative Commons Public Domain Dedication waiver (http://creativecommons.org/publicdomain/zero/1.0/) applies to the data made available in this article, unless otherwise stated. 
hospital-based data [3, 12-18]. Few studies have systematically evaluated multiple factors in prospective and unselected data series of consecutive ischemic stroke patients [19-23].

Physical activity (PA) activity before stroke as measured by self-report adds to the risk of poor outcome.

Epidemiologic studies have consistently suggested an association between PA and the risk of stroke [24-27]. $\mathrm{PA}$ is recommended to reduce the risk of first-ever and possibly the risk of recurrent stroke [24, 28-30]. Low PA may lower the individual capacity to cope with the metabolic and other stressful sequelae after cerebral ischemia.

The aim of this study was to identify predictors of one-year-functional outcome in patients with first-ever ischemic stroke, using five-year case series data from a prospective, population-based stroke registry. In particular, we tested the hypothesis that lack of self-reported recent PA increases risk of poor functional outcome after IS. Besides the well-established risk-factors, inflammatory parameters such as leukocyte count and fibrinogen were added to our analysis as previous studies showed an effect of a high inflammatory response on stroke outcome [31, 32].

\section{Methods}

The "Ludwigshafen Stroke Study" (LuSSt) is a prospective population-based stroke register in Ludwigshafen at Rhine in Germany, that started on January 1 st, 2006 [33].

In order to achieve complete case ascertainment, multiple overlapping methods of patient identification were used as described previously [33]. Case ascertainment of hospitalized patients was ensured by collaboration with all hospitals in the city of Ludwigshafen and hospitals in the region. To identify all non-hospitalized stroke patients, general practitioners, specialists in internal medicine, and neurologists practicing in Ludwigshafen were informed about the register before study initiation and were contacted together with nursing and residential homes. All patients treated at "Klinikum Ludwigshafen" were examined by a member of the study team, including an interview based on a structured questionnaire as described previously [34]. We intended to keep the questions as simple as possible for interviews in acutely ill patients. All patients who have been treated outside "Klinikum Ludwigshafen" and gave informed consent, were examined by a member of the study team. In the other patients data were obtained by the attending physician and transmitted to the study center in pseudonymised form. In all patients with informed consent follow-up investigations were performed by telephone 1 , 3 and 12 months after stroke utilizing a standardized questionnaire. If patients were unable to provide informations, a next-of-kin was interviewed. In patients without informed consent, or without response to multiple telephone and letter contact attempts, survival and death information was obtained by the population registration authority. LuSSt has been approved by the ethics committee of the Landesärztekammer RhinelandPalatinate and by the data protection commissioner of Rhineland-Palatinate.

Stroke was defined according to the definition of the World Health Organization (WHO) [35]. Stroke subtype classification was based on the results of brain imaging, discriminating between IS, intracerebral hemorrhage $(\mathrm{ICH})$, and subarachnoid hemorrhage (SAH). In case brain imaging was unavailable stroke type was defined as undetermined. The present analysis comprises only patients with first-ever ischemic stroke up to December 31st, 2010. Patients with a first ischemic stroke and a history of transient ischemic attack (TIA) were coded as first-ever ischemic stroke according to comparable population-based stroke registries [36]. Patients with recurrent stroke, TIA, SAH and ICH were excluded for present analysis.

\section{Outcome parameters and risk factors}

Stroke severity was determined at hospital admission using the National Institute of Health Stroke Scale (NIHSS) [37]. In order to assess functional status prior to stroke and functional outcome after first-ever ischemic stroke, modified Rankin Scale (mRS) was used [38, 39]. MRS is a 7-point scale ranging from 0 (no symptoms) to 6 (death). A score of 2 or less indicates functional independence [40]. Loss of independence in daily life was defined as a mRS $>2$ summarizing patients that had survived first 12 months after stroke with significant disabilities, and deceased ones. Cardiovascular risk factors were defined according to current guidelines as described previously [34, 41, 42]. Definitions have already been described earlier [34, 43]. In brief, hypertension was diagnosed if the patient was on antihypertensive medication on admission, if hypertension had been diagnosed before by a physician or if blood pressure was > $140 / 90 \mathrm{mmHg}$ in two or more measurements $>3$ days after stroke. Diabetes mellitus was defined in subjects with fasting blood glucose level above $125 \mathrm{mg} / \mathrm{dl}$ in venous blood, present anti-diabetic medication at hospital or known diagnosis of diabetes mellitus. Diagnosis of atrial fibrillation (AF) has been made if permanent or paroxysmal AF was present on ECG or long-term monitoring and additionally, in case of a history of this diagnosis. All in-patients with cholesterol-lowering medication, fasting cholesterol levels $>200 \mathrm{mg} / \mathrm{dl}$ or LDL-cholesterol > $140 \mathrm{mg} / \mathrm{dl}$ lead to diagnosis of Hypercholesterolemia. We defined current smoking as present daily usage of any kind of tobacco (at least one cigarette, cigar, cigarillo or pipe). We classified history of smoking as smoking for any 
period of at least 6 months. Patients with previous angina pectoris, myocardial infarction, coronary stenting or coronary artery bypass were selected as subjects with coronary artery disease (CAD) [34]. Patients with medical history of peripheral artery disease (PAD), arterial bypass surgery, stenting vessels of lower limbs and patients with present intermittent claudication or history of intermittent claudication of vascular origin were diagnosed PAD. Alcohol consumption as measured by self-report was coded if $>1$ drink per week was consumed on a regular base. Another selection criteria was consumption of alcohol in the past.

We used definition of the German Olympic Sports Association for PA as formerly described: PA as any leisure-time motor activity that had its aim in itself or was performed for no other purpose than to improve or maintain physical fitness [43]. Therefore, all activities such as walking were defined as PA and had been included. However, PA during work, PA on the way to or from employment or activities like gardening were not considered. All subjects were asked whether they had regularly performed sports during the months before stroke [30,43]. Regular PA was acknowledged as such activity at least once a week.

C-Reactive Protein (CRP) [particle-enhanced immunoturbidimetric assay CRPL3 (cobas ${ }^{\circ}$ )], fibrinogen (Clauss method on IL Coagulation Systems, Instrumentation Laboratory) and leukocyte count (XE analyserXE-2100; Sysmex) were determined $<48 \mathrm{~h}$ after admission.

\section{Medical treatment}

Thrombolysis was defined as intravenous application of recombined tissue plasmin activator (rt-PA). During the early years of LuSSt, mechanical recanalisation was not a standard in acute stroke therapy, and therefore not captured in the database. Antiplatetlet treatment included usage of one or more of these drugs: acetylsalicyl acid, clopidogrel, dipyridamol with acetylsalicylic acid and inhibitors of glycopeptide IIb/IIIa.

\section{Classification of stroke etiology}

We used a modification of the TOAST (Trial of Org 10,172 in Acute Stroke Treatment) criteria to define etiological subtypes of ischemic stroke [44]. Stroke due to large-artery atherosclerosis, cardioembolism, small-artery occlusion, stroke of other determined cause and stroke of undetermined etiology (except such from two or more competing etiologies) were diagnosed according to the TOAST criteria. In addition, we diagnosed 'probable atherothrombotic stroke' in such patients with stenosis < $50 \%$ diameter reduction on duplex sonography, CT-, MRor digital subtraction angiography and additional brain infarction(s) $>1.5 \mathrm{~cm}$ in the absence of any source of cardioembolism. This category is comparable to "athero thrombotic stroke" in the PERFORM study [45]. In patients with more than one potential cause for stroke, etiology was assigned to the most likely causative me chanism according to the SSS-TOAST classification [46]. Patients with stroke of unknown etiology were analyzed retrospectively, specifically using embolic strokes of undetermined source criteria (ESUS) and reclassified in cryptogenic ESUS, cryptogenic NON-ESUS or stroke of undetermined source (incomplete work-up or concurrent stroke). Classification was performed by experienced neurologists of the study team [47]. Controversial diagnoses were discussed and agreed in study meetings.

\section{Statistical methods}

For univariate analyses $x^{2}$-test, t-test with and without log-transformation and the Wilcoxon test were used as appropriate. For multivariate analysis, logistic regression was used. Variables being significant in univariate analyses were included in multivariable logistic regression analysis using the backward elimination procedure. To analyse the influence of early deaths after stroke, we compared our full dataset (Model A) with results after excluding patients who died early within the first 7 days after stroke (Model B). In further analysis, patients with "first ever ischemic stroke of unknown cause" were divided into three groups: "cryptogenic ESUS", "cryptogenic NON-ESUS" and "stroke of undetermined source" (stroke with incomplete work-up or concurrent stroke) (Model C).

All data were analysed using SAS 9.4 software (SAS Institute, North Carolina). All tests were performed for two-sided testing. Level of significance was set to $\alpha=$ 0.05 for all tests.

\section{Results}

Between January 1st, 2006 and December 31st, 2010, 1547 cases of first-ever ischemic stroke were registered in LuSSt. One-year follow-up information was available for 1370 subjects $(88.6 \%, 677$ women and 693 men). Information on mRS prior to stroke was available in 930 patients among whom 63 patients $(4.6 \%)$ had a mRS $>2$. No significant differences between patients with and without follow-up existed regarding age, sex and NIHSS at admission ( $p>0.1$, respectively). Among the $1370 \mathrm{pa}-$ tients, 717 patients $(52.3 \%)$ had poor outcome with loss of functional independence including 251 (18.3\%) patients who had died within the first year.

Clinical characteristics of all patients by one-year functional outcome are shown in Table 1. In univariate analysis, female sex, higher age, higher NIHSS score at admission, stroke etiology, higher leukocyte count, higher fibrinogen level, antiplatelet drugs before stroke, intravenous thrombolysis, arterial hypertension, $\mathrm{AF}$, CAD, hypercholesterolemia, diabetes mellitus, PAD, 
Table 1 Baseline characteristics, clinical characteristics and cerebrovascular risk factors by functional-outcome in 1370 patients with first-ever ischemic stroke - univariate analysis

\begin{tabular}{|c|c|c|c|c|}
\hline \multirow{3}{*}{$\begin{array}{l}\text { Predictor variable (number of } \\
\text { missing observations total) }\end{array}$} & \multicolumn{4}{|c|}{ One-year functional outcome } \\
\hline & \multicolumn{3}{|c|}{ N (\%) ${ }^{\circledR}$ Median (lower-upper quartile) } & \multirow{2}{*}{$\begin{array}{l}P \\
\text { value }\end{array}$} \\
\hline & Total $(n=1370)$ & $\mathrm{mRS} \leq 2(n=653)$ & $\mathrm{mRS}>2(n=717)$ & \\
\hline $\operatorname{Sex}(0)$ & & & & $<0.01$ \\
\hline Men & $693(50.6)$ & $385(59)$ & $308(43)$ & \\
\hline Women & $677(49.4)$ & $268(41)$ & $409(57)$ & \\
\hline Age (mean \pm SD;years) $(0)$ & $71.6 ; \pm 13$ & $66.1 ; \pm 12.3$ & $76.6 ; \pm 11.4$ & $<0.01$ \\
\hline \multicolumn{5}{|l|}{ Vascular risk factors } \\
\hline Arterial hypertension (11) & & & & $<0.01$ \\
\hline Yes & $1195(87.9)$ & $549(84.6)$ & $646(91)$ & \\
\hline No & $164(12.1)$ & $100(15.4)$ & $64(9)$ & \\
\hline Atrial fibrillation (36) & & & & $<0.01$ \\
\hline Yes & $391(29.3)$ & $112(17.6)$ & 279 (39.9) & \\
\hline No & $943(70.7)$ & $523(82.4)$ & $420(60.1)$ & \\
\hline Coronary heart disease (46) & & & & $<0.01$ \\
\hline Yes & $304(23)$ & $125(19.7)$ & 179 (25.9) & \\
\hline No & $1020(77)$ & $509(80.3)$ & $511(74.1)$ & \\
\hline Hypercholesterolemia (36) & & & & $<0.01$ \\
\hline Yes & $884(66.3)$ & $465(72.5)$ & $419(60.5)$ & \\
\hline No & $450(33.7)$ & $176(27.5)$ & $274(39.5)$ & \\
\hline Diabetes (20) & & & & $<0.01$ \\
\hline Yes & $422(31.3)$ & $167(25.9)$ & $255(36.1)$ & \\
\hline No & $928(68.7)$ & $477(74.1)$ & $451(63.9)$ & \\
\hline Peripheral arterial disease (51) & & & & $<0.01$ \\
\hline Yes & $132(10)$ & $46(7.3)$ & $86(12.6)$ & \\
\hline No & $1187(90)$ & $588(92.7)$ & $599(87.4)$ & \\
\hline Smoking (0) & & & & $<0.01$ \\
\hline Yes, actually & $305(22.3)$ & $184(28.2)$ & $121(16.9)$ & \\
\hline Yes, in the past & $394(28.8)$ & $196(30)$ & $198(27.6)$ & \\
\hline No & $520(38)$ & $224(34.3)$ & $296(41.3)$ & \\
\hline Unknown & $151(11)$ & $49(7.5)$ & $102(14.2)$ & \\
\hline Consumption of alcohol ${ }^{a}(80)$ & & & & $<0.01$ \\
\hline Yes, actually & $504(39.1)$ & $277(44.3)$ & $227(34.1)$ & \\
\hline Yes, in the past & $38(2.9)$ & $17(2.7)$ & $21(3.2)$ & \\
\hline No & $665(51.6)$ & $302(48.3)$ & $363(54.6)$ & \\
\hline Unknown & $83(6.4)$ & $29(4.7)$ & $54(8.1)$ & \\
\hline Regular physical activity (0) & & & & $<0.01$ \\
\hline Yes & $266(19.4)$ & $187(28.6)$ & $79(11)$ & \\
\hline No & $1104(80.6)$ & $466(71.4)$ & $638(89)$ & \\
\hline \multicolumn{5}{|l|}{ Clinical characteristics on admission } \\
\hline NIHSS $(33)^{b}$ & $3(2-6)$ & $2(1-4)$ & $5(3-11)$ & $<0.01$ \\
\hline TOAST (0) & & & & $<0.01$ \\
\hline Probable atherothrombotic & $208(15.2)$ & $98(15)$ & $110(15.3)$ & \\
\hline Cardioembolic & $422(30.8)$ & $143(21.9)$ & $279(39)$ & \\
\hline
\end{tabular}


Table 1 Baseline characteristics, clinical characteristics and cerebrovascular risk factors by functional-outcome in 1370 patients with first-ever ischemic stroke - univariate analysis (Continued)

\begin{tabular}{|c|c|c|c|c|}
\hline \multirow{3}{*}{$\begin{array}{l}\text { Predictor variable (number of } \\
\text { missing observations total) }\end{array}$} & \multicolumn{4}{|c|}{ One-year functional outcome } \\
\hline & \multicolumn{3}{|c|}{ N (\%) ${ }^{\&}$ Median (lower-upper quartile) } & \multirow{2}{*}{$\begin{array}{l}p \\
\text { value }\end{array}$} \\
\hline & Total $(n=1370)$ & $\mathrm{mRS} \leq 2(n=653)$ & $\mathrm{mRS}>2(n=717)$ & \\
\hline Large-artery atherosclerosis & $192(14)$ & $85(13)$ & $107(14.9)$ & \\
\hline Small-artery occlusion & $369(27)$ & $237(36.3)$ & $132(18.4)$ & \\
\hline Other determined & $62(4.5)$ & $28(4.3)$ & $34(4.7)$ & \\
\hline Unknown & $117(8.5)$ & $62(9.5)$ & $55(7.7)$ & \\
\hline Leukocytes $(47)^{\mathrm{b}}$ & $8.3(6.8-10.2)$ & $7.9(6.6-9.7)$ & $8.6(7.0-10.7)$ & $<0.01$ \\
\hline Fibrinogen $(86)^{b}$ & $370(318-434)$ & $356(309-412)$ & $386(329-455)$ & $<0.01$ \\
\hline Antiplatlet drugs (0) & & & & $<0.01$ \\
\hline Yes & $480(35)$ & $197(30.2)$ & $283(39.5)$ & \\
\hline No & $890(65)$ & $456(69.8)$ & $434(60.5)$ & \\
\hline Lysis therapy (0) & & & & $<0.01$ \\
\hline Yes & $124(9.1)$ & $37(5.7)$ & $87(12.1)$ & \\
\hline No & $1246(90.9)$ & $616(94.3)$ & $630(87.9)$ & \\
\hline \multicolumn{5}{|l|}{ Clinical characteristics at discharge } \\
\hline NIHSS $(109)^{b}$ & $2(1-4)$ & $1(0-2)$ & $3(1-7)$ & $<0.01$ \\
\hline \multicolumn{5}{|l|}{ mRS (94) } \\
\hline$\leq 2(0-2)$ & $838(65.7)$ & $573(92)$ & $265(40.6)$ & $<0.01$ \\
\hline$>2(3-6)$ & 438 (34.3) & $50(8)$ & $388(59.4)$ & \\
\hline
\end{tabular}

Comparisons by $\mathrm{X}^{2}$-test, Student's t-test with and without log-transformation and Wilcoxon test as appropriate

mRS modified Rankin Scale, N number, NIHSS National Institutes of Health Stroke Scale, SD standard deviation, TOAST Trial of ORG 10172 in Acute Stroke Treatment; ${ }^{\text {a }}>1$ drink per week; ${ }^{b}$ Quartiles

smoking status, alcohol consumption, regular PA prior to stroke and $\mathrm{mRS}>2$ at discharge were associated with one-year poor functional outcome or loss of independence. Among 117 patients with ischemic stroke of unknown etiology, stroke workup was incomplete in 39 (33.3\%) patients, cryptogenic stroke was diagnosed in 60 (51.3\%) patients and more than one possible etiology for ischemic stroke was evident in 18 patients (15.4\%). Among patients with cryptogenic stroke, ESUS was diagnosed in $40(66.7 \%)$ patients.

In multivariate analysis, lack of regular PA prior to stroke (OR 1.7; CI 1.1-2.5) independently predicted poor outcome together with female sex (OR 1.5; CI 1.12.1), higher age (65-74: OR 1.7; CI 1.1-2.8, 75-84 years: OR 3.3; CI 2.1-5.3; $\geq 85$ years OR 14.5; CI 7.4-28.5), higher NIHSS on admission (OR 1.2; CI 1.1-1.2), diabetes mellitus (OR 1.8; CI 1.3-2.5), probable atherothrombotic stroke (OR 1.8; CI 1.1-2.8) $\mathrm{mRS}>2$ at hospital discharge (OR 8.9; CI 6.0-13.0) and leukocyte count of $>9.000 / \mathrm{mm} 3$ (OR 1.4; CI 1.0-1.9); (Table 2, Model A). Threshold that was reported in previous studies [48]. Exclusion of patients who died $<7$ days after stroke (Model B) resulted in comparable results.

Subclassifying patients with unknown stroke etiology the diagnosis of cryptogenic ESUS showed a trend towards loss of functional outcome or death (OR 2.2; CI 0.9-5.5) whereas cryptogenic Non-ESUS stroke did not (OR 1.3; CI 0.5-3.7) (Table 2, Model C).

\section{Discussion}

In addition to well known predictors of stroke outcome we identified lack of regular PA prior to stroke, high leukocyte count, probable atherothrombotic stroke etiology as independent predictors of poor functional outcome. Stroke severity (measured by NIHSS or mRS), diabetes mellitus and higher age are well established independent predictors for poor stroke outcome [7, 4953]. Recently published scoring systems also used parameters like arterial hypertension, AF, higher age, sex, blood glucose, level of consciousness, stroke type or severity to predict stroke outcome $[3,7,54,55]$. Factors like arterial hypertension, AF, CAD, hypercholesterolemia, PAD, smoking status and alcohol consumption were not independent predictors for loss of functional independence in our population. This may partly be explained by too low numbers of subjects in our study, resulting in insufficient statistical power to detect predictors with moderate impact. Moreover, differences between study populations in risk factor control and compliance to medication intake (e.g. oral anticoagulants 
Table 2 Results of multivariate logistic regression analysis on 1-year functional outcome after first-ever ischemic stroke. Model A (all observations), Model B (excluding patients that had died early within 0-7 days after hospital admission) and Model C (all observations with subanalysis of the first-ever ischemic stroke "Unknown cause"). Observations with one or more missing variables have been dropped from multivariate analysis. Bold values indicate significance at $p<0.05$. Adjusted for age, diabetes mellitus and stroke severity

\begin{tabular}{|c|c|c|c|c|c|c|}
\hline \multirow[t]{2}{*}{ Predictor variable } & Model A & $n=1234$ & Model B & $n=1230$ & Model C & $n=1234$ \\
\hline & OR $(95 \% \mathrm{Cl})$ & $p$ value & OR $(95 \% \mathrm{Cl})$ & $p$ value & OR $(95 \% \mathrm{Cl})$ & $p$ value \\
\hline \multicolumn{7}{|l|}{ Sex } \\
\hline$(W$ vs $M)$ & $1.5(1.1-2.1)$ & 0.01 & $1.5(1.1-2.1)$ & 0.01 & $1.5(1.1-2.1)$ & 0.01 \\
\hline \multicolumn{7}{|l|}{ Age, years (vs 55-64) } \\
\hline$<55$ & $0.4(0.2-0.8)$ & 0.01 & $0.3(0.2-0.8)$ & 0.01 & $0.4(0.2-0.8)$ & 0.01 \\
\hline $65-74$ & $1.7(1.1-2.8)$ & 0.03 & $1.7(1.1-2.8)$ & 0.03 & $1.7(1.0-2.8)$ & 0.03 \\
\hline $75-84$ & $3.3(2.1-5.3)$ & $<0.01$ & $3.3(2.1-5.3)$ & $<0.01$ & $3.3(2.0-5.3)$ & $<0.01$ \\
\hline$\geq 85$ & $14.5(7.4-28.5)$ & $<0.01$ & $14.5(7.4-28.5)$ & $<0.01$ & $14.4(7.4-28.3)$ & $<0.01$ \\
\hline \multicolumn{7}{|l|}{ Regular Physical Activity } \\
\hline (No vs Yes) & $1.7(1.1-2.5)$ & $<0.01$ & $1.7(1.1-2.5)$ & $<0.01$ & $1.7(1.1-2.5)$ & $<0.01$ \\
\hline \multicolumn{7}{|l|}{ Diabetes } \\
\hline (Yes vs No) & $1.8(1.3-2.5)$ & $<0.01$ & $1.9(1.3-2.95$ & $<0.01$ & $1.8(1.3-2.5)$ & $<0.01$ \\
\hline \multicolumn{7}{|l|}{ Leukocyte count } \\
\hline$\left(\geq 9 \mathrm{vs}<9 \times 1000 / \mathrm{mm}^{3}\right)$ & $1.4(1.0-1.9)$ & 0.04 & $1.4(1.0-1.9)$ & 0.05 & $1.4(1.0-1.9)$ & 0.04 \\
\hline \multicolumn{7}{|l|}{ TOAST } \\
\hline \multicolumn{7}{|l|}{ (vs Small-artery occlusion) } \\
\hline Probable atherothrombotic & $1.8(1.1-2.8)$ & 0.02 & $1.8(1.0-2.8)$ & 0.02 & $1.8(1.1-2.8)$ & 0.02 \\
\hline Cardioembolic & $1.4(0.9-2.1)$ & 0.12 & $1.4(0.9-2.1)$ & 0.13 & $1.4(0.9-2.1)$ & 0.12 \\
\hline $\begin{array}{l}\text { Large-arthery } \\
\text { Atherosclerosis }\end{array}$ & $1.4(0.9-2.3)$ & 0.17 & $1.4(0.9-2.3)$ & 0.17 & $1.4(0.9-2.3)$ & 0.17 \\
\hline Other determined & $2.0(0.9-4.4)$ & 0.09 & $2.0(0.9-4.4)$ & 0.09 & $2.0(0.9-4.4)$ & 0.09 \\
\hline Unkown & $1.5(0.8-3.0)$ & 0.21 & $1.5(0.8-3.0)$ & 0.21 & & \\
\hline Cryptogenic ESUS & & & & & $2.2(0.9-5.5)$ & 0.10 \\
\hline Cryptogenic NON-ESUS & & & & & $1.3(0.5-3.7)$ & 0.62 \\
\hline Undetermined source & & & & & $0.9(0.2-3.8)$ & 0.94 \\
\hline \multicolumn{7}{|l|}{ mRS at hospital discharge } \\
\hline$(\geq 3$ vs $<3)$ & $8.9(6.0-13.3)$ & $<0.01$ & $8.9(6.0-13.3)$ & $<0.01$ & $8.9(6.0-13.4)$ & $<0.01$ \\
\hline \multicolumn{7}{|l|}{ NIHSS on admission } \\
\hline (per point) & $1.2(1.1-1.2)$ & $<0.01$ & $1.2(1.1-1.2)$ & $<0.01$ & $1.2(1.1-1.2)$ & $<0.01$ \\
\hline
\end{tabular}

ESUS embolic stroke of unknown source, $m R S$ modified Rankin Scale, NON-ESUS no embolic stroke of unknown source, $N$ number, NIHSS National Institutes of Health Stroke Scale, SD standard deviation, TOAST Trial of ORG 10172 in Acute Stroke Treatment;

in AF) may be accountable for variations between studies.

Lack of regular physical activity is a modifiable risk factor for both, ischemic and hemorrhage stroke [5658]. PA reduces stroke risk by lowering blood pressure, improving lipid and glucose metabolism and endothelial function. Further benefits are reduction of thrombocyte aggregation and blood viscosity [58]. Recently published studies showed endothelial function and atherogenesis to be influenced by PA $[59,60]$. Improved physical fitness results in better control of risk factors like hypertension and diabetes mellitus and this could have contributed to the beneficial effect of PA on stroke outcome in our study. Patients who had engaged in regular PA may be in better physical and mental conditions and have more capacity to cope with the sequelae of stroke. An association between prognosis after stroke and previous PA had been reported in few studies so far [56-58]. In the Framingham study there was no reduction for stroke risk beyond a moderate level of physical activity [26]. We therefore used comparable low threshold $(\geq 1$ per week) to define regular PA in our study. Physical 
handicap before stroke was seldom observed (mRS $>2$ in only $4.9 \%$ of patients) in our patients and did thus, not explain the association between lack of PA and outcome. A strength of our study is higher number of cases and prospective study design compared to other studies. However, our findings should be ascertained by further prospective studies. PA is a modifiable lifestyle risk factor with a major importance in preemptive strategies to prevent strokes and improve mid-term stroke outcome. For future stroke care, PA as a modifiable risk factor should get more focus in stroke research as well as in primary and secondary stroke care. Documenting and focusing on regular PA might have great impact in primary stroke care leading to better stroke outcomes and more functional independence. Being physically active in mid-life increases the odds of being active in old age [61]. However, more research is necessary, e.g. to find out how much PA preceeding first-ever ischemic stroke reduces stroke severity. Visual representation of the overall distribution of mRS 12 months post stroke draws a clear picture of difference by PA activity pre stroke. Even if a part of the difference is attributable to other confounding factors, like NIHSS on admission and mRS at hospital discharge, the cumulative barchart visualizes striking difference of outcomes in favour of PA. In contrast to other studies, we used definition of the German Olympic Sports Association. Registration of leisure-time motor activity only might result in underestimation of physical activity.

Higher leukocyte count was associated with lack of functional independence in our population indicating that the strength of the early inflammatory response heralds poor prognosis independent of clinical stroke severity and factors that are known to contribute to leukocyte counts such as smoking and diabetes mellitus. Infection before ischemia is an established stroke trigger factor which may partly explain the association between leukocyte count and poor prognosis, as well as larger infarct volume which was not investigated in our study $[31,32]$. Blood samples were taken within $24 \mathrm{~h}$ in the majority of patients; therefore it is unlikely that leukocytosis was due to stroke related infections such as post-stroke pneumonia.

In line with other studies, female sex proved to be an independent predictor for lack of functional independence $[7,62]$. Gall et al. hypothesized that females are more vulnerable than men because of differences in chronic diseases, socioeconomic status and medical histories [63]. Females are more likely to suffer from severe strokes [62, 64]. A further reason might be the sex-related differences in muscular strength, or different approaches to handle their disabilities. This difference between sexes may increase in the elderly, because the observed decline in muscle strength with aging is also related to a reduction in PA, normally different between sexes. In people older than 65 years, less than one third of all women performed some PA - compared to men with $47.9 \%$. Elderly women with a higher body mass index have a lower status of PA [65]. Moreover, female patients have a higher risk of walking with a cane [66]. More focus on PA in middle-life could improve level of PA in elderly people [61]. Additionally, more frequent occurrence of depression and lack of social support may increase probability for loss of functional independence in females [7, 55, 67]. However, most authors used univariate analyses and did not adjust for confounders.

Regarding stroke etiology, probable atherothrombotic stroke was an independent predictor for loss of functional independence in our population. The category of stroke of probable atherothrombotic etiology includes patients with distinct signs of non-stenosing arteriosclerosis as a marker of probable atherosclerotic plaques mostly at the orifices of small penetrating arteries, such as lenticulostriate arteries. CAD and PAD, that were associated with loss of functional independence in univariate but not in multivariate analysis are other common atherosclerotic diseases and may have contributed to some degree to the effect of this etiologic subgroup. This group may also include some patients with cardioembolic strokes due to non-detected AF. In contrast to other studies, cardioembolism was not independently associated with poor functional outcome in multivariate analysis. Cardioembolic stroke results in higher stroke severity. Adjustment for NIHSS and mRS at discharge presumeably prompted lack of significance of cardioembolism in our study.

In 117 patients stroke etiology was classified as stroke of unknown origin. Further analysis identified cryptogenic strokes and ESUS as main contributors to this group. Two thirds of patients with cryptogenic strokes were diagnosed as cryptogenic ESUS and tended to be associated with loss of functional independence, a finding that did not reach statistical significance due to small numbers. These cases may partly represent patients with non-detected AF and without any kind of anticoagulation. More effort in detecting AF in patients with ESUS may reduce recurrence of IS and improve functional outcome.

There are strengths and limitations to this study. The data were derived from a population-based stroke register, including both hospitalized and non-hospitalized patients without age-restrictions. Data have been collected prospectively by applying standardized protocols using multiple notification sources widely ensuring complete case ascertainment. Robust quality of case ascertainment is indicated by stable incidence rates over time. A high rate of neuroimaging (98.2\%) assures high reliability of first-ever ischemic stroke diagnosis. An intense clinical 
work-up together with the application of modified TOAST criteria resulted in a low number of patients with undefined stroke causes [48]. This enabled us to study a relatively large cohort of unselected patients, resulting in sufficient statistical power to determine differences in stroke outcome. Our study is characterized by a high rate of follow-up and low rates of missing values $(<5 \%)$. Observed early death rates in our study were similar to findings in other population-based stroke registers [36, 68].

Limitations of our current work include the lack of data on the quality of risk factor control and the exploratory character of our results on factors like previous PA without possibility to reanalyze the detected results in a derivation sample. Further statistical limitation is lack of a power as LuSSt is primarily descriptive. Additionally, PA after stroke has not been assessed and an overestimation in amount of sports activity might result in another bias: acquisition of self-reported patients data increase the possibility of a misclassification bias. Distant events are often not precisely recalled, also raising the possibility of recall bias, particularly for sports in early adulthood. In contrast to other studies on physical activity using WHO definition, we used definition of the German Olympic Sports Association. Furthermore, poor outcome had not included standardized patient reported outcome measures like Euro-QOL-5, Frenchay Activities Index, HAD's depression or PROMIS-10 [55, 69-71].

\section{Conclusion}

In addition to broadly accepted risk factors for poor functional outcome we found that lack of PA prior to stroke, high leukocyte count at admission and probable atherothrombotic stroke etiology may constitute important independent predictors of loss of functional independence after first-ever ischemic stroke.

\footnotetext{
Abbreviations

AF: Atrial fibrillation; CAD: Coronary artery disease; Cl: Confidence interval; CRP: C-Reactive Protein; ESUS: Embolic stroke of unknown source; ICH: Intracerebral hemorrhage; IS: Ischemic stroke; LuSSt: Ludwigshafen Stroke Study; mRS: Modified Rankin Scale; NIHSS: National Institute of Health Stroke Scale; OR: Odds ratio; PA : Physical activity; PAD: Peripheral artery disease; rt-PA: Recombined tissue plasmin activator; SAH: Subarachnoid hemorrhage; TIA: Transient ischemic attack; WHO: World Health Organization
}

\section{Acknowledgements}

Not applicable

\section{Funding}

The Ludwigshafen Stroke Register had received unrestricted funding by Boehringer Ingelheim, Sanofi-Aventis and BASF. Data analysis was supported by a grant from the Deutsche Forschungsgemeinschaft (DFG; GR1102/6-1). Study design, data collection, data analysis and data interpretation were independent from any study sponsor.

LuSSt is part of the German Competence Network Stroke.

\section{Availability of data and materials}

The datasets used and/or analysed during the current study are available from the corresponding author on reasonable request.

\section{Authors' contributions}

CU, FP, AJG were responsible for study concept and design. CU and FP were responsible for data acquisition and mainly wrote the manuscript. VG and FB were major contributors in data acquisition. AS and HB mainly contributed to statistical analysis. VG, FB, AS, HB and AJG critically revised the manuscript for important intelectual content. All authors read and approved the final manuscript.

\section{Ethics approval and consent to participate}

All patients with stroke or TIA in the City of Ludwigshafen were asked for written informed consent. In all patients with informed consent follow-up investigations could have been performed by telephone 1, 3 and 12 months after stroke utilizing a standardized questionnaire. In patients without informed consent survival and death information was obtained by the population registration authority. LuSSt has been approved by the ethics committee of the Landesärztekammer Rhineland-Palatinate and by the data protection commissioner of Rhineland-Palatinate.

\section{Consent for publication}

Not applicable

\section{Competing interests}

The authors declare that they have no competing interests.

\section{Publisher's Note}

Springer Nature remains neutral with regard to jurisdictional claims in published maps and institutional affiliations.

\section{Author details}

'Department of Neurology, University of Heidelberg, Städtisches Klinikum Ludwigshafen am Rhein, Bremserstr. 79, 67063 Ludwigshafen, Germany. ${ }^{2}$ University of Mannheim, Department of Dermatology, Theodor-Kutzer-Ufer 1-3, Mannheim 68167, Germany. ${ }^{3}$ University of Heidelberg, Institute of Public Health, Im Neuenheimer Feld 324, Heidelberg, Germany. ${ }^{4}$ Institute of Medical Biometry and Epidemiology, University Medical Center Hamburg-Eppendorf, Hamburg, Germany.

Received: 9 December 2017 Accepted: 25 October 2018

Published online: 03 November 2018

\section{References}

1. Summers D, Leonard A, Wentworth D, Saver JL, Simpson J, Spilker JA, et al. Comprehensive overview of nursing and interdisciplinary care of the acute ischemic stroke patient: a scientific statement from the American Heart Association. Stroke. 2009;40:2911-44. https://doi.org/10.1161/STROKEAHA. 109.192362.

2. Baek JH, Kim K, Lee Y-B, Park K-H, Park H-M, Shin D-J, et al. Predicting stroke outcome using clinical-versus imaging-based scoring system. J Stroke Cerebrovasc Dis. 2015;24:642-8. https://doi.org/10.1016/j. jstrokecerebrovasdis.2014.10.009.

3. Ntaios G, Faouzi M, Ferrari J, Lang W, Vemmos K, Michel P. An integer-based score to predict functional outcome in acute ischemic stroke: the ASTRAL score. Neurology. 2012;78:1916-22. https://doi.org/10.1212/WNL. ob013e318259e221.

4. Cooray C, Mazya M, Bottai M, Dorado L, Skoda O, Toni D, et al. External validation of the ASTRAL and DRAGON scores for prediction of functional outcome in stroke. Stroke. 2016;47:1493-9. https://doi.org/10.1161/ STROKEAHA.116.012802.

5. Ntaios G, Gioulekas F, Papavasileiou V, Strbian D, Michel P. ASTRAL, DRAGON and SEDAN scores predict stroke outcome more accurately than physicians. Eur J Neurol. 2016;23:1651-7. https://doi.org/10.1111/ene.13100.

6. Appelros P, Nydevik I, Viitanen M. Poor outcome after first-ever stroke: predictors for death, dependency, and recurrent stroke within the first year. Stroke. 2003;34:122-6. https://doi.org/10.1161/01.STR.0000047852.05842.3C.

7. Weimar C, Ziegler A, Konig IR, Diener H-C. Predicting functional outcome and survival after acute ischemic stroke. J Neurol. 2002;249:888-95. https:// doi.org/10.1007/s00415-002-0755-8.

8. Hankey GJ. Long-term outcome after ischaemic stroke/transient ischaemic attack. Cerebrovasc Dis. 2003;16:14-9. https://doi.org/10.1159/000069936.

9. Phan TG, Clissold BB, Ma H, van Ly J, Srikanth V. Predicting disability after ischemic stroke based on comorbidity index and stroke severity-from the 
virtual international stroke trials archive-acute collaboration. Front Neurol. 2017:8:192. https://doi.org/10.3389/fneur.2017.00192.

10. Wouters A, Nysten C, Thijs $V$, Lemmens R. Prediction of outcome in patients with acute ischemic stroke based on initial severity and improvement in the first 24 h. Front Neurol. 2018;9:308. https://doi.org/10.3389/fneur.2018.00308.

11. Palm F, Pussinen PJ, Safer A, Tervahartiala T, Sorsa T, Urbanek C, et al. Serum matrix metalloproteinase-8, tissue inhibitor of metalloproteinase and myeloperoxidase in ischemic stroke. Atherosclerosis. 2018;271:9-14. https:// doi.org/10.1016/j.atherosclerosis.2018.02.012.

12. Kwakkel G, Wagenaar RC, Kollen BJ, Lankhorst GJ. Predicting disability in stroke--a critical review of the literature. Age Ageing. 1996;25:479-89.

13. Counsell C, Dennis M. Systematic review of prognostic models in patients with acute stroke. Cerebrovasc Dis. 2001;12:159-70.

14. Fonarow GC, Pan W, Saver JL, Smith EE, Reeves MJ, Broderick JP, et al. Comparison of 30-day mortality models for profiling hospital performance in acute ischemic stroke with vs without adjustment for stroke severity. JAMA. 2012;308:257-64. https://doi.org/10.1001/jama.2012.7870.

15. Keyhani S, Cheng E, Arling G, Li X, Myers L, Ofner S, et al. Does the inclusion of stroke severity in a 30-day mortality model change standardized mortality rates at veterans affairs hospitals? Circ Cardiovasc Qual Outcomes. 2012:5:508-13. https://doi.org/10.1161/CIRCOUTCOMES.111.962936.

16. Wang W-Y, Sang W-W, Jin D, Yan S-M, Hong Y, Zhang H, Yang X. The prognostic value of the iScore, the PLAN score, and the ASTRAL score in acute ischemic stroke. J Stroke Cerebrovasc Dis. 2017;26:1233-8. https://doi. org/10.1016/j.jstrokecerebrovasdis.2017.01.013.

17. Wang A, Pednekar N, Lehrer R, Todo A, Sahni R, Marks S, Stiefel MF. DRAGON score predicts functional outcomes in acute ischemic stroke patients receiving both intravenous tissue plasminogen activator and endovascular therapy. Surg Neurol Int. 2017;8:149. https://doi.org/10.4103/ 2152-7806.210993.

18. Flint AC, Kamel H, Rao VA, Cullen SP, Faigeles BS, Smith WS. Validation of the totaled health risks in vascular events (THRIVE) score for outcome prediction in endovascular stroke treatment. Int J Stroke. 2014;9:32-9. https://doi.org/10.1111/j.1747-4949.2012.00872.x.

19. Veerbeek JM, Kwakkel G, van Wegen EEH, JCF K, Heymans MW. Early prediction of outcome of activities of daily living after stroke: a systematic review. Stroke. 2011;42:1482-8. https://doi.org/10.1161/STROKEAHA.110. 604090 .

20. Rost NS, Bottle A, Lee J-M, Randall M, Middleton S, Shaw L, et al. Stroke severity is a crucial predictor of outcome: an international prospective validation study. J Am Heart Assoc. 2016. https://doi.org/10.1161/JAHA.115. 002433.

21. Shen B, Yang X, Sui R-B, Yang B. The prognostic value of the THRIVE score, the iscore score and the ASTRAL score in Chinese patients with acute ischemic stroke. J Stroke Cerebrovasc Dis. 2018. https://doi.org/10.1016/j. jstrokecerebrovasdis.2018.06.011.

22. Forti $P$, Maioli F, Procaccianti G, Nativio V, Lega $M-V$, Coveri M, et al. Independent predictors of ischemic stroke in the elderly: prospective data from a stroke unit. Neurology. 2013;80:29-38. https://doi.org/10.1212/WNL. Ob013e31827b1a41.

23. Hung K-H, Lai JC-Y, Hsu K-N, Hu C, Chang H-C, Chen C-N, et al. Gender gap and risk factors for poor stroke outcomes: a single hospital-based prospective cohort study. J Stroke Cerebrovasc Dis. 2018;27:2250-8. https:// doi.org/10.1016/j.jstrokecerebrovasdis.2018.04.014.

24. Lee CD, Folsom AR, Blair SN. Physical activity and stroke risk: a meta-analysis. Stroke. 2003;34:2475-81. https://doi.org/10.1161/01.STR.0000091843.02517. 9D.

25. Autenrieth CS, Evenson KR, Yatsuya H, Shahar E, Baggett C, Rosamond WD Association between physical activity and risk of stroke subtypes: the atherosclerosis risk in communities study. Neuroepidemiology. 2013;40:10916. https://doi.org/10.1159/000342151.

26. Kiely DK, Wolf PA, Cupples LA, Beiser AS, Kannel WB. Physical activity and stroke risk: the Framingham study. Am J Epidemiol. 1994;140:608-20.

27. Kubota Y, Iso H, Yamagishi K, Sawada N, Tsugane S. Daily total physical activity and incident stroke: the Japan public health center-based prospective study. Stroke. 2017:48:1730-6. https://doi.org/10.1161/ STROKEAHA.117.017560.

28. Gordon NF, Gulanick M, Costa F, Fletcher G, Franklin BA, Roth EJ, Shephard T. Physical activity and exercise recommendations for stroke survivors: an American Heart Association scientific statement from the council on clinical cardiology, subcommittee on exercise, cardiac rehabilitation, and prevention; the council on cardiovascular nursing; the council on nutrition, physical activity, and metabolism; and the stroke council. Circulation. 2004; 109:2031-41. https://doi.org/10.1161/01.CIR.0000126280.65777.A4.

29. Rist PM, Capistrant BD, Mayeda ER, Liu SY, Glymour MM. Physical activity, but not body mass index, predicts less disability before and after stroke. Neurology. 2017:88:1718-26. https://doi.org/10.1212/WNL.0000000000003888.

30. Wannamethee G, Shaper AG. Physical activity and stroke in British middle aged men. BMJ. 1992;304:597-601.

31. Elkind MSV. Infectious burden: a new risk factor and treatment target for atherosclerosis. Infect Disord Drug Targets. 2010;10:84-90.

32. Huang W-Y, Peng T-I, Weng W-C, Chien Y-Y, Wu C-L, Lee M, Chen K-H. Higher leukocyte count is associated with higher risk of 3-year mortality in non-diabetic patients with first-ever ischemic stroke. J Neurol Sci. 2012;316: 93-8. https://doi.org/10.1016/j.jns.2012.01.018.

33. Palm F, Urbanek C, Rose S, Buggle F, Bode B, Hennerici MG, et al. Stroke incidence and survival in Ludwigshafen am Rhein, Germany: the Ludwigshafen stroke study (LuSSt). Stroke. 2010;41:1865-70. https://doi.org/ 10.1161/STROKEAHA.110.592642.

34. Palm F, Urbanek C, Wolf J, Buggle F, Kleemann T, Hennerici MG, et al. Etiology, risk factors and sex differences in ischemic stroke in the Ludwigshafen stroke study, a population-based stroke registry. Cerebrovasc Dis. 2012;33:69-75. https://doi.org/10.1159/000333417.

35. Hatano S. Experience from a multicentre stroke register: a preliminary report. Bull World Health Organ. 1976;54:541-53.

36. Wolfe CD, Giroud M, Kolominsky-Rabas P, Dundas R, Lemesle M, Heuschmann $P$, Rudd A. Variations in stroke incidence and survival in 3 areas of Europe. European registries of stroke (EROS) collaboration. Stroke. 2000:31:2074-9.

37. Goldstein LB, Bertels C, Davis JN. Interrater reliability of the NIH stroke scale. Arch Neurol. 1989;46:660-2.

38. Rankin J. Cerebral vascular accidents in patients over the age of 60. III. Diagnosis and treatment. Scott Med J. 1957;2:254-68.

39. Savio K, Della Pietra GL, Oddone E, Reggiani M, Leone MA. Reliability of the modified Rankin scale applied by telephone. Neurol Int. 2013;5:e2. https:// doi.org/10.4081/ni.2013.e2

40. Berkhemer OA, Fransen PSS, Beumer D, van den Berg LA, Lingsma HF, Yoo $\mathrm{AJ}$, et al. A randomized trial of intraarterial treatment for acute ischemic stroke. N Engl J Med. 2015;372:11-20. https://doi.org/10.1056/ NEJMoa1411587.

41. The sixth report of the Joint National Committee on prevention, detection, evaluation, and treatment of high blood pressure. Arch Intern Med. 1997; 157:2413-46.

42. Balkau B. The DECODE study. Diabetes epidemiology: collaborative analysis of diagnostic criteria in Europe. Diabetes Metab. 2000;26:282-6.

43. Grau AJ, Barth C, Geletneky B, Ling P, Palm F, Lichy C, et al. Association between recent sports activity, sports activity in young adulthood, and stroke. Stroke. 2009;40:426-31. https://doi.org/10.1161/STROKEAHA.108. 527978.

44. Adams HPJR, Bendixen BH, Kappelle LJ, Biller J, Love BB, Gordon DL, Marsh EE. Classification of subtype of acute ischemic stroke. Definitions for use in a multicenter clinical trial. TOAST. Trial of org 10172 in acute stroke treatment. Stroke. 1993;24:35-41.

45. Hennerici MG, Bots ML, Ford I, Laurent S, Touboul PJ. Rationale, design and population baseline characteristics of the PERFORM vascular project: an ancillary study of the prevention of cerebrovascular and cardiovascular events of ischemic origin with teRutroban in patients with a history of ischemic strOke or tRansient ischeMic attack (PERFORM) trial. Cardiovasc Drugs Ther. 2010;24:175-80. https://doi.org/10.1007/s10557-010-6231-2.

46. Ay H, Furie KL, Singhal A, Smith WS, Sorensen AG, Koroshetz WJ. An evidence-based causative classification system for acute ischemic stroke. Ann Neurol. 2005;58:688-97. https://doi.org/10.1002/ana.20617.

47. Hart RG, Diener H-C, Coutts SB, Easton JD, Granger CB, O'Donnell MJ, et al. Embolic strokes of undetermined source: the case for a new clinical construct. Lancet Neurol. 2014;13:429-38. https://doi.org/10.1016/S14744422(13)70310-7.

48. Palm F, Dos Santos M, Urbanek C, Greulich M, Zimmer K, Safer A, et al. Stroke seasonality associations with subtype, etiology and laboratory results in the Ludwigshafen stroke study (LuSSt). Eur J Epidemiol. 2013;28:373-81. https://doi.org/10.1007/s10654-013-9772-4.

49. Kenmuir $C L$, Hammer M, Jovin $T$, Reddy V, Wechsler $L$, Jadhav A. Predictors of outcome in patients presenting with acute ischemic stroke and mild 
stroke scale scores. J Stroke Cerebrovasc Dis. 2015;24:1685-9. https://doi. org/10.1016/j.jstrokecerebrovasdis.2015.03.042

50. Kaarisalo MM, Raiha I, Sivenius J, Immonen-Raiha P, Lehtonen A, Sarti C, et al. Diabetes worsens the outcome of acute ischemic stroke. Diabetes Res Clin Pract. 2005;69:293-8. https://doi.org/10.1016/j.diabres.2005.02.001.

51. Heuschmann PU, Kolominsky-Rabas PL, Misselwitz B, Hermanek P, Leffmann C, Janzen RWC, et al. Predictors of in-hospital mortality and attributable risks of death after ischemic stroke: the German stroke registers study group. Arch Intern Med. 2004;164:1761-8. https://doi.org/10.1001/archinte.164.16.1761.

52. Jia Q, Zhao X, Wang C, Wang Y, Yan Y, Li H, et al. Diabetes and poor outcomes within 6 months after acute ischemic stroke: the China National Stroke Registry. Stroke. 2011;42:2758-62. https://doi.org/10.1161/ STROKEAHA.111.621649.

53. Ullberg T, Zia E, Petersson J, Norrving B. Changes in functional outcome over the first year after stroke: an observational study from the Swedish stroke register. Stroke. 2015;46:389-94. https://doi.org/10.1161/STROKEAHA. 114.006538 .

54. Bejot Y, Jacquin A, Daubail B, Durier J, Giroud M. Population-based validation of the iscore for predicting mortality and early functional outcome in ischemic stroke patients. Neuroepidemiology. 2013;41:169-73. https://doi.org/10.1159/000354634.

55. Jönsson A-C, Delavaran H, Iwarsson S, Ståhl A, Norrving B, Lindgren A. Functional status and patient-reported outcome 10 years after stroke: the Lund stroke register. Stroke. 2014;45:1784-90. https://doi.org/10.1161/ STROKEAHA. 114.005164.

56. Armstrong MEG, Green J, Reeves GK, Beral V, Cairns BJ. Frequent physical activity may not reduce vascular disease risk as much as moderate activity: large prospective study of women in the United Kingdom. Circulation. 2015; 131:721-9. https://doi.org/10.1161/CIRCULATIONAHA.114.010296.

57. Krarup L-H, Truelsen T, Gluud C, Andersen G, Zeng X, Korv J, et al. Prestroke physical activity is associated with severity and long-term outcome from first-ever stroke. Neurology. 2008;71:1313-8. https://doi.org/10.1212/01.wnl. 0000327667.48013.9f

58. Reimers CD, Knapp G, Reimers AK. Exercise as stroke prophylaxis. Dtsch Arztebl Int. 2009;106:715-21. https://doi.org/10.3238/arztbl.2009.0715.

59. Chin K, Di Zhao TM, Martin SS, Ndumele CE, Florido R, et al. Physical activity, Vitamin $\mathrm{D}$, and incident atherosclerotic cardiovascular disease in Whites and Blacks: the ARIC Study. J Clin Endocrinol Metab. 2017. https://doi.org/10. 1210/jc.2016-3743.

60. Mueller UM, Walther C, Adam J, Fikenzer K, Erbs S, Mende M, et al. Endothelial function in children and adolescents is mainly influenced by age, sex and physical activity- an analysis of reactive hyperemic peripheral artery tonometry. Circ J. 2017. https://doi.org/10.1253/circj.CJ-16-0994.

61. Aggio D, Papacosta O, Lennon L, Whincup P, Wannamethee G, Jefferis BJ. Association between physical activity levels in mid-life with physical activity in old age: a 20-year tracking study in a prospective cohort. BMJ Open. 2017;7:e017378. https://doi.org/10.1136/bmjopen-2017-017378.

62. Synhaeve NE, Arntz RM, van Alebeek ME, van Pamelen J, Maaijwee NAM, Rutten-Jacobs $L C A$, et al. Women have a poorer very long-term functional outcome after stroke among adults aged 18-50 years: the FUTURE study. J Neurol. 2016;263:1099-105. https://doi.org/10.1007/s00415-016-8042-2.

63. Gall SL, Tran PL, Martin K, Blizzard L, Srikanth V. Sex differences in long-term outcomes after stroke: functional outcomes, handicap, and quality of life. Stroke. 2012;43:1982-7. https://doi.org/10.1161/STROKEAHA.111.632547.

64. Mozaffarian D, Benjamin EJ, Go AS, Arnett DK, Blaha MJ, Cushman M, et al. Heart disease and stroke statistics--2015 update: a report from the American Heart Association. Circulation. 2015;131:e29-322. https://doi.org/10.1161/CIR. 0000000000000152

65. Sinaki M, Nwaogwugwu NC, Phillips BE, Mokri MP. Effect of gender, age, and anthropometry on axial and appendicular muscle strength. Am J Phys Med Rehabil. 2001;80:330-8.

66. Paolucci S, Bragoni M, Coiro P, de Angelis D, Fusco FR, Morelli D, et al. Is sex a prognostic factor in stroke rehabilitation? A matched comparison. Stroke. 2006;37:2989-94. https://doi.org/10.1161/01.STR.0000248456.41647.3d.

67. Friberg L, Benson L, Rosenqvist M, Lip GYH. Assessment of female sex as a risk factor in atrial fibrillation in Sweden: nationwide retrospective cohort study. BMJ. 2012;344:e3522. https://doi.org/10.1136/bmj.e3522.

68. Lainay C, Benzenine E, Durier J, Daubail B, Giroud M, Quantin C, Bejot Y. Hospitalization within the first year after stroke: the Dijon stroke registry. Stroke. 2015:46:190-6. https://doi.org/10.1161/STROKEAHA.114.007429.
69. Salinas J, Sprinkhuizen SM, Ackerson T, Bernhardt J, Davie C, George MG, et al. An international standard set of patient-centered outcome measures after stroke. Stroke. 2016;47:180-6. https://doi.org/10.1161/STROKEAHA.115.010898.

70. Revicki DA, Kawata AK, Harnam N, Chen W-H, Hays RD, Cella D. Predicting EuroQol (EQ-5D) scores from the patient-reported outcomes measurement information system (PROMIS) global items and domain item banks in a United States sample. Qual Life Res. 2009;18:783-91. https:/doi.org/10.1007/ s11136-009-9489-8.

71. Crichton SL, Bray BD, McKevitt C, Rudd AG, Wolfe CDA. Patient outcomes up to 15 years after stroke: survival, disability, quality of life, cognition and mental health. J Neurol Neurosurg Psychiatry. 2016;87:1091-8. https://doi. org/10.1136/jnnp-2016-313361

\section{Ready to submit your research? Choose BMC and benefit from:}

- fast, convenient online submission

- thorough peer review by experienced researchers in your field

- rapid publication on acceptance

- support for research data, including large and complex data types

- gold Open Access which fosters wider collaboration and increased citations

- maximum visibility for your research: over $100 \mathrm{M}$ website views per year

At BMC, research is always in progress.

Learn more biomedcentral.com/submissions 